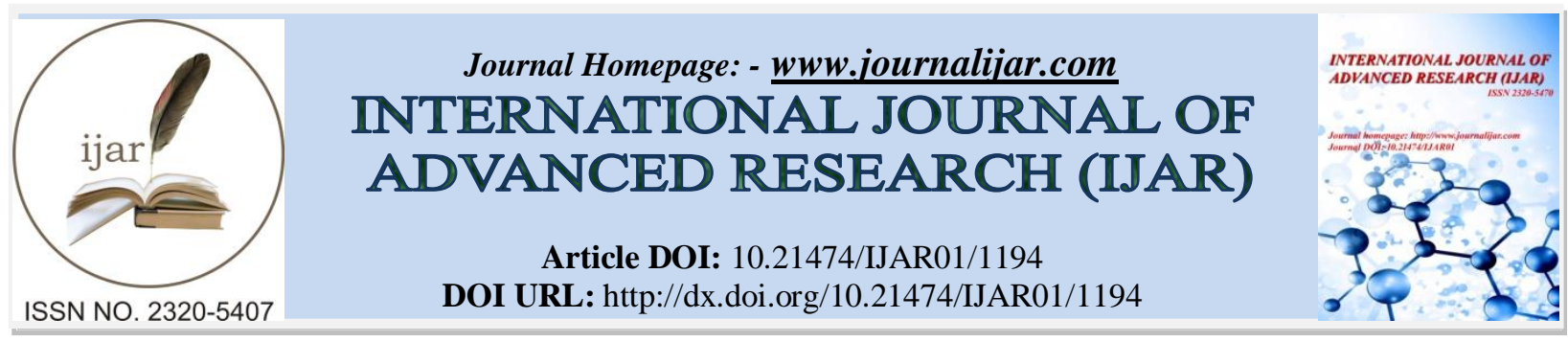

RESEARCH ARTICLE

\title{
ANDY WARHOL'S PSYCHOLOGICAL ANALYSIS AND ITS EFFECTS ON HIS WORKS.
}

Islamic Azad University, Iran.

Yasaman Haddadzadeh Zarandy.

\section{Manuscript Info}

Manuscript History

Received: 10 June 2016

Final Accepted: 19 July 2016

Published: August 2016

Key words:-

AndyWarhol, psychology, pop art.

\section{Abstract}

The most popular pop artist in America is AndyWarhol, whose artistic experiences are very higher than the usual borders of the painting art borders. He is an artist who, entering the art world, worked in various field such as painting, photography, movies, graphical arts and so on. AndyWarhol's works, after a century quarter of his arising as an artist is 1952 until his death in 1987, were symbols of the consuming culture in the avant-garde methods. His works interfaces between the art and the mass culture. It can be said that AndyWarhol is the embodied form of a star, in whom all creator, introducer and an actor futures are gathered together. But he has an unknown personality, who has been always hidden in the back of a shelter. Despite his successes, he always suffered from an internal fear which was with him until his death time and effected his selected themes. In this article, it has been attempted to investigate his works titles and their relationship with his internal modes. The method of this research is a psychological trend, and the tool method is documental-library.

Copy Right, IJAR, 2016,. All rights reserved.

\section{Introduction:-}

Adulthood life's distortion is caused by childish sadness. Mental tensions and the attempts of a child extend to his/her adulthood. The emotional patterns of childhood, usually mold the adulthood personality. In most cases, the first onset of neurological disorders such as psychopathic personality and psychosis has been in childhood. Almost all adult disorders and disturbances stem from insecurity, inadequacy and guilt senses. The human characters aremade up of the emotional feelings. As soon as the feelings in children and adolescents be formed, by aging the paths and ways take various forms. In this way, unsafe children may become alcoholics or criminal in adultor neurotic and extremely sensitive; while others may become dominant or timid. Children who are emotionally turmoil, are not only not the same as their behaviors, but this mess will not elicit the same degree of sensitivity.Insecurity usually makes the person feel alone in the world is not acceptable. He feels that the environment is threatening and it is likely that it will harm him. Basically, he believes that the world is full of danger and know that something terrible happen to him. When these feelings become more intense in a person, he may take different behavior patterns, such as psychopathic behavior, madness, fear, anxiety, phobias, obsessive and neurotic behavior with high tension often leads to illness, pain, and the physical discomfort.The main reason for insecurity in one's early life is evident, especially in the early years of the school's events. These causes mostly related to relationships with parents, anda bit of sibling relationships.Power and influence act within the family that bring insecurity positive or negative insecurity. Of course, social, cultural and economic senses rarely exacerbate these 
senses. Discrimination because of race, family, religion and creed, color, physical appearance or way of dressing all of those things that make sense of rejection in the child.Andy Warhol was in enigmatic and mysterious character, whose paintings reveal fear in life, his movies reveal the secret fear of death, and these films arose to meet the needs of Faustian about maintenance fleeting moment.

Fear of life - fear of death: In Andy Warhol art, these two complementary feelings, may seem contradictory, but they are the scopes of his belief in the areas of life and art. Now the question arises is: What could be the reason of these fears, which is typical of Warhol's life? Perhaps somewhat with his ambiguous character analysis, we can understand the concept of his works and his choice of subject, and the techniques used by him.

\section{Fear:-}

"Fear is one of the phenomena that play a decisive role in human evolution, it also explains the formation of the human personality and social relations, which the true measure of its role in psychology and psychoanalysis, as well as in sociology is very important."(Shining Path, 2006: 185)

Freud believed that the fear or anxiety, is the root of all nervous states. And yet he believes that fears have has an intimate connection with issues such as sex and so on. Whether or not we accept above mentioned ideas, the fear is very important and should be seriously addressed. The fear is natural and some cases, while in others it is not, and the reason of this feeling should be asked and treated totally, otherwise it can affect all of a person's life.

"If there is a fear, there are two things: it is a natural state, or a rare condition. Since the rare state is less than usual or more than that, therefore, the fear that too frequently and on every occasion arises, is rare and unusual. Normal fears are beneficial for health. But other types of fears harm the person's mental personality and behavior. Also introspect, pusillanimity and cowardice, stuttering and traits such, prevent the normal growth of the person and of the manifestations of fear (Elkoussy, 1986:31).

You can find different manifestations of rare fears and they can reveal themselves as various kinds in the person's life. We must know that these fears are the basic of Psychosis. However, lives of many people are full of fears, and many people don't know the cause of their fears and assume their fearful behaviors to be natural.

\section{Kind of fears:-}

Freud divided the fears into two basic types:

1. Threaded or real fears

2. Basic or non-specific fears

In the first type, fears are associated with certain subjects and characters, such as fear of animals, darkness, death, etc. But in the second, fears not associated with any particular issue and is constantly changing and is not based on any issue fixed. Someone with the latter case, is pessimistic and sad that is waiting at any moment something horrible to happen, Freud calls the state anxiety nervous. (Elkoussy,1986: 31)

In the first type usually called fear or phobias; the person is afraid of something or a place which in itself is not dangerous to humans, but it produces fear for the person. In the second type the cause of fear is not known, and the risky factor in this kind of fear is that, the person is trying to make sense of the external factors. The current Psychoanalysis findings teach us that the reason of these fears is the risk to humans instinctively triggers. This means that a human instincts are not satisfied, the effect of suppressing on unconscious is the fear. "Fear and anxiety are used as synonymous terms and it is incorrect; but in fact they can clearly be distinguished from each other in terms of their relation with risk. Anxiety represents a special case of looking out for danger or prepare for it, although the risk can be unknown. Fear requires a certain issue that should be in fear. Terror is the name given to a condition that where, someone is faced with a danger without being prepared to it. (Freud, 2003: 30)

\section{Panic:-}

"In Greek, the word Panic is called phobia. For the first time the word phobia was used by Stanley Hall (1914) in psychology. He ranked more than 132 samples of panic and presented them with their derivatives of the Greek words: fear of cats, acrophobia, and fear of flowers, fear of thunder and fear of bacteria" (Shining Path, 2006: 185).

Undoubtedly all the various forms of Panic are can be regarded as abnormal fears, and their common character in connection with their role in human mind are expressed. 
"This is common that people with phobias understand themselves, their illness workmanship incorrectly": They feel weak and vulnerable and often hold a kind of shame which often leads them to hide the anxiety of the people "(Andre, 2010: 73).

In people with phobias extreme caution related to living environment (psychological fear), puts them in an emotional state of intense physical stress (Physical fear).

\section{Traumatic neurosis:-}

"The situation that after severe mechanical shock and railway accidents and other incidents involving danger to life occurs, is known for a long time and have been described and named as traumatic neurosis. World War II led to the emergence of a large number of these type of diseases, but the event is at least an end to the temptation that we assume the cause of the disease to a nervous system which is forced by a mechanical agent. The picture that draws symptoms of traumatic neurosis draws in frequency of motor skills is similar to hysteria; but as a rule about quite obvious signs of mental illness - in this case is similar to complain or melancholy- goes farther. Yet a thorough explanation of the neurosis of war or traumatic neurosis arising from the peace has not been achieved. In the case of war neurosis, the fact that the symptoms sometimes appear without the intervention of any purely mechanical force, seems clear and at the same time it is also confusing. In the case of traumatic neurosis two common characteristics are manifested as obvious: First, it appears that the major factor causing them is based on panic and terror; second wound and injury which arrive at the same time act as a rule opposed to the development of neurosis "(Freud, 2003: 30).

In people who have a traumatic neurosis, it is possible even in sleep mode theincident occur to them. It is also possible that an event be associated with the mishaps happened to them. In any case we do not know whether people who have traumatic neurosis address in waking life to an incident that happened to them and perhaps they don't want to follow the incident and do forget it. "Human beings are prone to accidents and incidents during the current life of our time in a variety of cars and planes, explosions, fires, earthquakes and so on. And their reaction is often shock to pretend that change is temporary and unsustainable imbalances in their character".

\section{Symptoms:-}

Shock may cause different symptoms, which are related to the severity and type of accident and the person's character. In general, symptoms include anger symptoms associated with anxiety: Person is disturbed and startled and jumps for any brief noise and has a difficulty in concentratingand gets tired. In almost half of cases, the patient sees nightmares at night that are related to the same incident and in very difficult problems may he/she be shocked and be unable to detect the location and time and generally forget even the memories of the incident. The patient heals with mental gentle treatment usually. Sometimes these reactions with guilt and grief and feelings of hostility become more complex, especially when someone in an accident is survived and other family members or friends are gone. In some people, the psychological symptoms for weeks or even months after the frightening accident occur, and this is usually when the member injured is present. This is called post-traumatic reactions and may include anxiety, headache, back pain, weakness, and discomfort part of the body that is affected. In some cases, severe accident hastens a secret disease, but sometimes traumatic reactions appear later in life when a person is to be experiencing an unenviable position (Birjandy, 1962: 155).

The cause of most of these symptoms is that, a world until the incident has been a safe and healthy one, has suddenly become horrible place, as the personal compromise is inadequate to deal with it. In the face of these events, the means of their psychological intervention is required and sometimes, especially in the event that some are damaged.

\section{Anxiety disorder:-}

"When anxiety attacks are repeated, become a particularly crippling, wild disease. Because of features very difficult for sudden attacks of anxiety, people who suffer from them, always fear of the occurrence of such, and feat the results (death or insanity). Many of them believe that they suffer from an illness that doctors are not able to detect it and conduct further medical tests. Others have completely changed their way of life and are withdrawn from some activities (e.g. field trips, job displacement ...)because those places can cause anxiety attacks. In anxiety disorders, the frequency, intensity and time of attack can vary from person to person. When attacks are frequent and severe, all 
causes are gathered of course, they usually appear early in the attack; unfinished consecutively attacks during which time the patient actually feels the early signs of attack. And most of the time while they are away can prevent it from progressing. Most of the time the difference in intensity, causes disruption of discipline and routine of daily life: Attacks on those who strictly avoid dangerous situations occur much less frequently, but this is to ignore price of the lot or permanent use of sedatives. Today we believe that the core of panic disorder is typicalinterpretation of bodily sensations: some of the physiological symptoms are more normal than the others (single palpitations, light dizziness, breathing difficulties or need to sigh) are the prelude to a panic attack for the person. This incorrect interpretation of feeling safe and unstable physical frightens the person and the horror develops the first impressions (the emotions that could soon disappear). This phenomenon is called the spiral of terror. That means panic disorder represents a very interesting phobia which is called introspection. That is, physical symptoms that indicate a real phobia is characterized by its focus. The disease, affects one to two percent of the population. It is noteworthy that panic disorder is no doubt that the pain of the world "(Andre, 2010: 36).

It can be said that anxiety attacks in people creates a kind of psychological fear which is always with them, and even if they are treated and have no attack interpret any single body activity as an attack.In fact, they tell their heart the disease and go so far as to really attack happens and be intense. Perhaps this suggestion is beginning to be generally distance themselves from their normal daily life and awaits the start of attacks at any moment.Perhaps these patients with psychotherapy sessions and work on them can be out of this state of mind and thoughts and return to normal life. "For example, more or less accurate description in this case we found a study of psychoanalysis from Japanese, which as a sign of a disease calledShinkeishitsu early this century described by psychoanalyst Shumai Morita: The more accurate feel we're on, it feels tighter, and more focused our attention on it ... So immediately consciously or unconsciously, the fear comes to us and fear triggered by a stimulus. In the case of repeated attack, the patient slowly becomes a victim of fear in everyday life and the attacks with be incremental ..." (Ibid: 36)

The pressure (stress) depends on the position of the person and the value that is attached to it. Stress that one cannot stand without symptoms and disturbance is called the tolerance of stress. In some people, compromise is in such a shaky basis that that the most minor stress may cause an unusual reaction on them; while people may be able to bear greater pressure. Pressure type is important in determining the overall strength of pressure and stress. The experience uncomfortable trauma may also make a person more vulnerable to a particular type of stress.

\section{Disturbing the balance:-}

"When the pressures inflicted is severe, and the person is unable to tolerate them, inevitably, he restores to the diversion of defense. This is the disturbing the equilibrium state whose physical or mental or social levels may occur. This imbalance in the body based on extensive studies of hormonal defenses that get the job done with the mediation of your nervous system has been described. And consists of three stages which include: 1) informative response that mobilizes the body's defenses 2) Stage where all the resources of the physical strength to cope breaks and maximum use possible of its existence to the body 3) the analysis stage where hormonal defense is broken and continued pressure causes death or the dissolution of the body. Even in stage 2 may also cause the symptoms severity" (Birjandy, 1962: 96).

In all these steps were described, as previously mentioned the human mind works in such a way that begins to defend itselfand is always on the alert. But since the pressure and anxiety entered is so high,the mind affects the whole body. And little by little goes so far as that cause madness or death. All these pressures, disturbances, anxiety, etc. can be social, cultural and economic searched that arise due to several reasons such as war, racism, family, religion and creed, color, physical appearance or method dressed and so on. All communities suffer the consequences of these factors, but the victims of these issues will certainly incur more losses; for this reason, the results of which is quite impressive on the individual and social character of these people.

\section{Fear of death:-}

"The man who does not feel the anxiety of death does not know that the natural world is the enemy of him, and seeks his kill and destroy, and inherently incapable of making him happy. He wants the world to fix up the details change. This man as a reformer, is shrewd and skilledand will act as the popular crowd, but never be a true revolutionary "(Hegel, 1979: 75).

Thinking about death from suicide and voluntary death to escape death, fear of death, the desire to kill and die, harassment, violence, war seeking, as well as any play with death or tease it is there today in the West thought. This 
attitude has affected the lives of people in all directions. Even the impact of this attitude can also be seen in the works of artists. An attitude that can be said is before the 60s was tabooand it could not even be articulated; it can be noted that two major wars in the 19th and 20th centuries have helped in the creation of this attitude. "Enthusiasm for not thinking to death, and most importantly, the wish to be not afraid of death, in the West of modern thought, from Descartes to Nietzsche, is obvious. In our culture, the fear of death is the same as death. So far the ideas cannot overcome the fear of death, man is afraid of death and destruction, and from this fear which is perhaps the most fundamental fear. Meanwhile the culture of East and West, in the past, believed that the power could be possible with emphasizes on heroism and the power to resist death. On the contrary, at that time, fear of death, was taboo, and accept or admit to it was a situation considered shameful for human. Thus the cult of society in every age, wants of all its citizens to not fear death and heroic stand against it "(Industrial, 2005: 34).

Here the hero in the mold may be considered in Warhol's worksand the use of movie stars and celebrities can be taken as some kind for fear of death and destruction and resistance.

Perhaps since the beginning of written history of the West, from epics Iliad and Odyssey and the era of the dominance of Christianity in Europe tragedy of death and violence, an important part of the culture of the West. In recent years, important books published on the subject in Europe and America. Philippe

(1- Mao,1972)

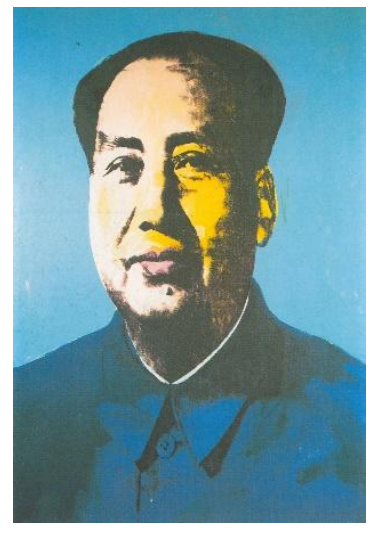

(2- Elizabeth Taylor)

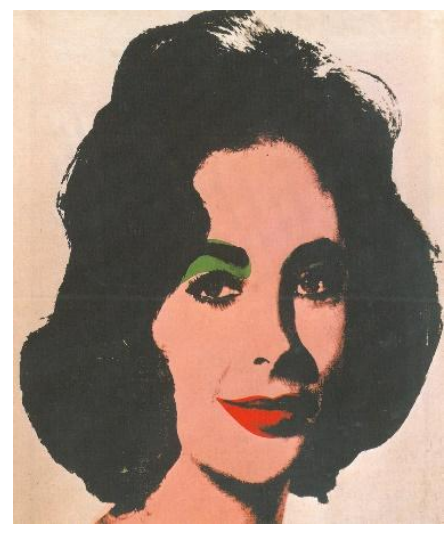

(3- Merilyn Monroe)

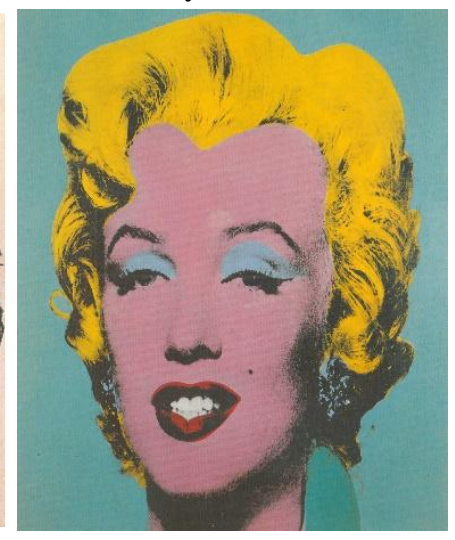

(4- Elvis Presley,1964)

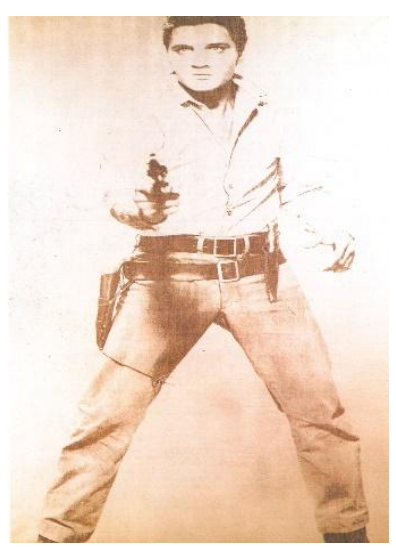

Aries (1914-1984) sees the roots of violence and death in the Judeo-Christian heritage of the West in which death has been at the center of its cultural life. While, as noted, even more than the spread of Christianity in Europe through Alexandria to Greece and Rome, the culture of ancient Greece and the Roman Empire already had a preoccupation with death. Since the beginning of the Renaissance thought life was gradually replaced by the idea of death And since Michelle and Francis Bacon deny the fear of death was taught in the West since Plato, was replaced with fear of death. With Descartes we come to joy of life and fear of death is stated together. The fear of death which is Hobbes' personal experience was considered very serious and sublimated in his political thought. Fear of death in the dialectic of master and servant relationship was theorized by Hegel, and Schopenhauer's philosophy of accepting death in life came in the form of denial. But rejection of death was obvious in thinkers like Spinoza and Nietzsche, especially after Nietzsche. Therefore, some believe that the denial of death gradually became popular of about 1900 in the West.From mid-twentieth century no longer a death in the civilized man was a taboo" (Ibid 4645).

Psychiatrists claim that fear of death, in intensity, in terms of post-process development (growth) is different in different people, because the fear of death during the process of development (growth) is experiencing a metamorphosis. If children have a good education, the education at best, only to hide the fear of death will help. In addition, the backlash through children with parents may be through normal replication.

\section{Andy Warhol:-}

Pop artist Andy Warhol, in his era was legendary. He cast a perfect example of the heroism in the story. Different birth dates have been released, but undoubtedly he was born between 1928 and 1931 . He claims that the 1930 date was fake and was born on June 6, 1928. It's hard to texts about the life of Andy Warhol achieved. His life is a kind of seasoning contradictions, and all the contradictions of his character and his life had pulled the mask. He was 
trained as a commercial artist, but all life wanted to be a full-fledged artist. In many of his works he used of celebrities. Somehow became a star himself (Honnef, 2006: 11).

"He, at the beginning, usedof lovely things, and showed positive aspects of daily life of Americans. But somewhere after death was linked to his work because he had realized at the end of life is the destruction "(Hadadzadeh, 2015: $60)$.

(5-Green Car Crash,1963)

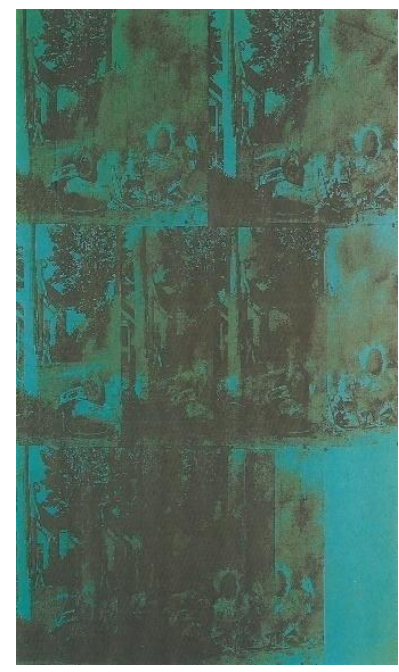

( 6- 129 die in jet,1962)

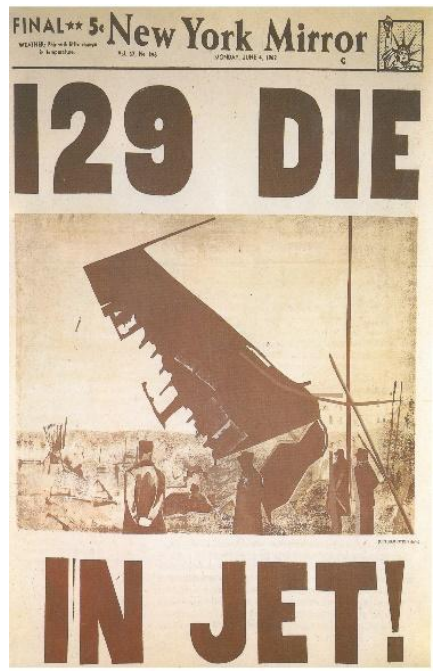

( 7- Jndy Garland,1956)

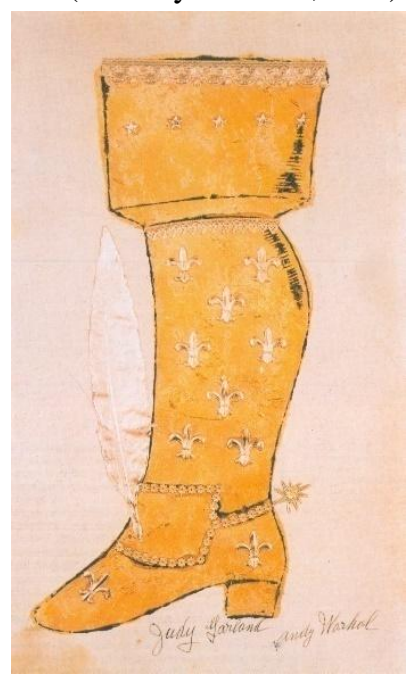

"Warhol was fully aware of characteristics of his works, not as a moralist nor behaved like a prophet. But like a child who had discovered what everyday images, wanted by any means available, death and evil consequences away of him. "(Pierre, 2004, 182-183)

Perhaps the use of silk-screen techniques led to mass-produce things. But there was another reason as to eliminate any feeling can be attributed in some way to the death. Removing any the effects feeling is a kind of death, which again is connected with the subject of death. "Time, enclosed repeated the same images and bring them to capture the moment" (Hadadzadeh, 2015: 61).

Iterative relationships is actually relevant with objects that appear critical function of bridging the real vacuum. So, people object that seek to perpetuate daydreams, even if the object of fantasy that can never be absolutely vacuum cover, even if those objects (which may be as background familiar defined), the first tail are enjoyable, at the moment of death before killing after stopping and stability.Repetitive rituals become habits, and even if there is no repeat of the deadly nature, the invisible bonds that connect us to the rest. As a result, we defend everything to our constant static sense, a movement in which freedom is truth and unchangeable "(Ragland, 2005: 345).

The same result is repeated in the works of Warhol, and somehow refers to the concept of death. Because no change is there and everything is repeated for before with the show after of death.

\section{Conclusions:-}

We can say that Andy Warhol had the insecurity problem which has its roots in his childhood. He was born in a family that was financially not in good condition, not much has seen his father and was raised by his mother. Perhaps the migration has a significant impact on the formation of his character; for example, always liked to be an American original and even change her his color to blonde. Always has been internalized anxiety and stress. Fear of the main factors in determining his life that can be said has affected his life at all stages. His fear was not a normal fear can be say it was some kind of phobia. Perhaps phobia of death or life, this phobia of death effect is evident in all his works. His phobia of death was so much that even wanted to have an exchange and be present everywhere. This is due to stand against the fear of death. It is evident in his works. Repetitive practices become accustomed and even if not fatal, but repeated inherently linked to the rest. He even used to repeat it in his personal life (using the same nutritional meals for the same, always using jeans or even naming all of her cats to a name). Andy Warhol has been traumatic neurosis disorder after the incident that happened to him. He was assassinated by Valerie Solanas in June 1968 and was seriously injured. This incident caused the disorder of Warhol; a condition occurs after danger to 
life; this disorder is similar to hysteria. Warhol throughout his life suffers from this disorder and every moment in fear and anxiety take over and even the smallest things returns his to the assassination event. And perhaps we can say that if Warhol had not died as a result of surgery could be wiped out by disease. The human brain after the accident as it is always on alert. And it's so much pressure and anxiety that goes up to the balance and the body disappears and the final stage is the collapse of body.

\section{References:-}

1. Andrew, Christopher, psychology, fear (phobia). Translation Jahangir MirzaJafar, ehran Third Printing, Publishing Ascension

2. Birjandy, P. (1970) abnormal psychology. Tehran, Tehran University Press

3. Pierre J. (2001), pop art: Pop art painters and sculptors school.Translation MitraRostampour, Second Edition, Tehran, process

4. Hegel, G. W. F. (1980).master and servant, translated by Hamid end, Third Edition, Tehran, al-Khwarizmi

5. Elqousi, A. (1986). Fear. Teacher Development, Number 34

6. Ragland, E. (2005). Lacan's notion of the death drive, Organon, No. 26 and 27

7. Shining, P. M. (2006). Fear and demographic character, Samarkand, 13 and 14

8. Sanati, M. (2004), Earn to Die in the West thought, Organon, No. 26 and 27

9. Freud, S. (2003) Beyond the pleasure principle, Organon, No. 21

10. Hadadzadeh, Z.(2014). The functions of visual creativity in new media at the works of Andy Warhol, Supervisor: Doctor Mohammad Reza Sharif-zadeh,Advisor: doctor Mir Ali Daryabeigi, Islamic Azad University (Tehran Central), University of the Arts and architecture

11. Honnef, K. (2007). Warhol, Germany, Taschen 